\title{
The Use of AI in a Pandemic Emergence: A Biolegal Discourse in the International Arena
}

\section{Randazzo S*}

Department of Law, Libera Università Mediterranea, Italy

Conceptual Paper

Volume 3 Issue 4

Received Date: September 30, 2020

*Corresponding author: Salvatore Randazzo, Professor of Roman Law and European Legal Roots, President of Bios \& Law Research Center, past Director of Global Bioethics and Law Research Center at University of Catania, Department of Law, LUM Jean Monnet S.S. $100 \mathrm{Km}$
Published Date: October 12, 2020

DOI: $10.23880 /$ abca- 16000140 18-70010 Casamassima, Bari, Italy, Email: randazzo@lum.it

\section{Conceptual Paper}

\section{Introduction}

The pandemic has resulted in an emergency situation that has called into question not only health perspectives but also shared values and established rules. The critical question being how best to face up to this cultural rather than legal emergency?. The debate is widespread across every scientific field involving jurists, philosophers, politicians. The applications of AI in this situation are manifold and of particular concern is the use of so-called Artificial Intelligence in the pandemic. One of the most interesting aspects, from an ethical and legal point of view is the use of artificial intelligence systems in monitoring social distance, i.e. the ways in which, through cameras, robotic systems and augmented reality, it is possible to calculate the geometric distance between people, triggering alerts whenever violations occur. A perspective that many scientists are engaged with but which is not new in the literature that has evoked sophisticated theories, starting from Game Theory and which is currently being developed to support new products and technologies in the field [1]. On the level of legal theory these systems undermine the most important ideas about individual freedom and its limitation because they concern the basic behavior of people, that is, their physical contact with other people.

This paper proposes a novel approach to understand and manage this complex issue that includes cross-cultural and cross-jurisdictional [2], but primarily addresses crosslegal and cross-ethics perspectives.

\section{A Cross-Legal Perspective: A Necessity}

Thelaw oftengoverns emergency situations. Both codified systems and Common Law systems have mechanisms for dealing with unexpected situations in terms of relationships between people, for example those of a contractual nature. Public emergencies are also regulated: for example, in the case of war, in which individual states and the international community apply precise rules, special courts and specific powers. What changes in the war against the pandemic? The factual conventions and legal perspectives at the level of domestic and international law tend to be modified

Fighting the pandemic is different from fighting another state or a coalition of states. The pandemic is a planetary emergency and this makes the approach to it critical in terms of the range of jurist's instruments both national and supranational that invariably presuppose a visible counterpart, an identifiable enemy to fight.

This emergency has also highlighted the lack of an effective international organization that can manage an event of this magnitude. The United Nations or the WHO does not have adequate power to impose a general directive on that of a single state. Therefore, the prevailing law must take cognizance of the new matter expeditiously in line with the gravity of the situation domestically and the wider international perspective. This is not a choice; it is a necessity.

International travel being a very good exemplar and the possibility of welcoming a traveler to a country or not: this is a national choice, but one that has international implications. Consider, for example, the civil liability of an airline that does not have appropriate safeguards in place to ensure that no passengeron their airline are positive or asymptomatic carriers. An intertwining of civil liabilities that makes 
ordinary instruments inadequate. For example, in Italian law the effectiveness of the application of article 2043 of the civil code and of extra-contractual liability in this situation is already difficult, but it becomes extremely difficult to use it in an international context because the international precedents concern cases of contagion liability that do not have the vagueness of Covid-19 infections (for example the Judgment of the European Court of Human Rights of 1 December 2009 -Appeal n.43134/95 -GN v. Italy, in a case of contagion following transfusions).

Therefore, only a cross-legal approach can support the efforts of politics but this approach still has to navigate the many difficulties in implementing a dialogue between autonomous and non-communicating legal systems. It is only with a historical reflection can we try to grasp connections and spaces for dialogue, especially between Civil Law and Common Law legal systems $[3,4]$.

\section{AI and Law the Core of the Problem}

One area where these legal problems become very serious is the use of Artificial Intelligence (AI) in a pandemic to control the population. In this case the problems of civil liability are linked to general and constitutional problems, from personal freedom to human rights, in the context of the use of AI tools in international spaces.

In this context, AI assumed a key role in the fight against the pandemic in 2020 [5,6]. Control of people on a planetary level in the name of a general interest is simply impossible in the current legal system: there is a lack of adequate international agreements and uniform norms in national legal systems. Even the analogical application of rules used for other scenarios (for example war) becomes difficult because the legal problem, in the case of the pandemic, is intertwined with the protection of human rights and with the fundamental principles accepted in the Constitutions of many countries of the world.

In this emergency, the gap in fundamental values has emerged in all its glory. Several Asian countries have adopted cyber-control measures of the population through geolocation and mass control based on facial recognition. Softer forms of control have been experimented with in other countries and are limited to telephonic controls.

All this teaches us two things. The first is that we need to work to align the international standard on fundamental rights and bridge the legal, but first of all, social and cultural gap among the countries of the world. The second is that the pandemic has changed many things and is also changing the law. The traditional categories of international law of treaties and rules posed by international organizations show its weakness when the international community is faced with a problem of this magnitude. It is necessary to reassess the guiding principles of these organizations to better equip them with more effective and immediate legal intervention tools that override national preferences in exceptional circumstances such as planetary emergency.

\section{Conclusion}

\section{A Bio-Legal Perspective: A Solution?}

And yet these solutions alone will not suffice. A cultural growth is needed that considers AI in all its complexity, which has three connected aspects: the practical need to control individuals, justified by a collective interest; the need to give global legal regulation, or at least widely shared, to forms and methods of control; the need to strengthen ethical awareness in the companies involved. A partial view, considering only one of these aspects, would not achieve the result, as demonstrated by the uncertainty of public actions in the United States. Nor does the approach of the Council of Europe help us, merely by recalling the limits set by article 10 of the European Convention on Human Rights of 1950 or Convention 108/1981 on the protection of individuals with reference to the automated processing of personal data. In these vacuities of uncertainty, doing nothing is not an option, informed decision must be made. The emergency must be regulated in line with best practice identified by either national or the international community. In the same way that international (as well as national) legal systems have provided for specific bodies, laws and processes for wartime, a similar preventive discipline is needed for this war, which is not without an antagonist, but has a specific and identified enemy: the virus. Exceptionality must be normality; it must be governed in advance by certain and accepted rules. Thus the collective fear of the advent of a disciplinary society, to use the terminology of Michel Foucault [7], which, evoking Jeremy Bentham's Panopticon, the prison building where it is possible to supervise all prisoners without their understanding [8], seems prediction of the control of bodies in the experience of the new digital Panopticon of the pandemic, such fear will be appeased by the awareness of a self-disciplined society [9], a safe but free society. Biopolitics will have to replace the bioethical awareness of politics and in so doing, establish a new and shared Law that will draw its strength from a broad acceptance and not from the imposition of predetermined and restrictive rules of personal freedom, even if they are fully justified by the need to defend the health of others and therefore the first form of freedom [10].

The approach does not demonize the countries that have taken excessive measures for our Western sensibility but to provide adequate tools to manage the emergency, reinventing 


\section{Annals of Bioethics \& Clinical Applications}

the emergency, as an opportunity for rebalancing the level of world democracy with respect to the protection of human rights.

The global challenge is clear: law, like medicine, cannot be unprepared for the emergency and in this way risk not only the health of citizens but also the health of democracy.

\section{References}

1. Reluga TC (2010) Game Theory of Social Distancing in Response to an Epidemic. PLoS Comput Biol 6(5).

2. Bennet B, Carney T (2010) Law, ethics and pandemic preparedness: the importance of cross-jurisdictional and cross-cultural perspectives. Australian and New Zealand Journal of Public Health 34(2): 106-112.

3. Randazzo S (2002) Roman Legal Tradition and American Law. The Riccobono Seminar of Roman law in Washington. Roman Legal Tradition 1: 123-144.
4. Randazzo S (2010) Roman Law vs US Law? The contribution of Roman law to a possible dialogue. Vita e Pensiero, pp: 1-2.

5. Yakobovitch D (2020) How to fight the Coronavirus with AI and Data Science. Medium 15: 2.

6. Ratnam G (2020) Can AI Fill in the Blanks About Coronavirus? Experts Think So. Government Technology.

7. Foucault M (1966) Words and things. An archeology of the human sciences, Gallimard.

8. Foucault M (1975) Monitor and Punish: Birth of Prison.

9. Timan T, Galič ZM, Koops BJ (2017) Surveillance Theory and its Implications for Law, The Oxford Handbook of the Law and Regulation of Technology.

10. Cristani M, Bue AD, Murino V, Setti F, Vinciarelli A (2020) The Visual Social Distancing Problem. Cornell University, pp: 9.

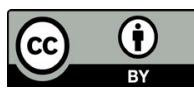

